white, black, and others. Multiple variables for chronic/acute comorbidities identified associated with outcomes. After adjustment using logistic regression, race was not associated with three in-hospital outcome variables: mortality $(\mathrm{p}=0.183)$, post-operative stroke $(\mathrm{p}=0.610)$ and discharge disposition $(\mathrm{p}=0.231)$.

Conclusions There were no differences in hospital outcome among races/ethnicities in endovascular thrombectomy outcomes for acute stroke patients in the Premier data. Racial/ ethnic disparities play role for patients' selection not for patients' outcome in endovascular thrombectomy.

Disclosures S. Park: None. M. Pilot: None. M. Alexander: 1; C; Consultant for Stryker Neurovascular, Medtronic, and Penumbra, Inc. A. Rosengart: None.

\section{P-009 ASPECTS DECAY DURING INTER-FACILITY TRANSFER IN PATIENTS WITH LARGE VESSEL OCCLUSION STROKES AND ITS IMPACT ON ELIGIBILITY FOR ENDOVASCULAR PROCEDURES}

${ }^{1} \mathrm{M}$ Mokin, ${ }^{2} \mathrm{R}$ Gupta, ${ }^{1} \mathrm{~W}$ Guerrero, ${ }^{1} \mathrm{D}$ Rose, ${ }^{1} \mathrm{~W}$ Burgin, ${ }^{1} \mathrm{~S}$ Sivakanthan. ${ }^{1}$ University of South Florida, Tampa, FL; ${ }^{2}$ Wellstar Neurosurgery, Marietta, GA

\subsection{6/neurintsurg-2016-012589.51}

Background Favorable imaging profile according to the Alberta Stroke Program Early CT Score (ASPECTS) on noncontrast head CT is a key criterion for the selection of patients with ischemic stroke from large vessel occlusion (LVO) for intraarterial (IA) revascularization therapies.

Objective The goal of our study was to analyze factors associated with changes in ASPECTS during inter-hospital transfer and to determine their impact on eligibility for endovascular procedures.

Methods We analyzed factors associated with changes in ASPECTS during inter-hospital transfer and their potential impact on eligibility for IA stroke therapies in patients with anterior circulation ischemic strokes. Clinical and demographic characteristics between patients with favorable and unfavorable imaging on repeat CT were compared. Favorable ASPECTS profile was defined as ASPECTS $\geq 6$, and unfavorable ASPECTS $<6$, based on the imaging criteria proposed by the AHA in the 2015 updated acute stroke guidelines.

Results Of the 50 transferred patients with anterior circulation LVO, 42 had favorable ASPECTS $\geq 6$ on CT imaging performed at outside hospital. 19 (45\%) of those 42 patients presented to an outside facility within 6 hours of stroke onset (mean time from symptom onset to head CT, $295 \pm 61 \mathrm{~min}$ ), whereas in 23 patients CT showed favorable ASPECTS with stroke onset beyond the 6 hour window (mean time from symptom onset to outside CT, $603 \pm 224 \mathrm{~min}$ ). Stroke evolution towards unfavorable ASPECTS occurred in 13 (31\%) out of 42 patients who initially had favorable imaging profile at outside hospitals. Higher NIHSS score was the only significant predictor of ASPECTS decay, whereas other clinical characteristics such as the use of intravenous thrombolysis and site of LVO (ICA versus MCA M1/M2) were similar between both groups.

Conclusions Our study showed that during inter-hospital transfer, one out of three patients with stroke from anterior circulation LVO becomes ineligible for IA thrombectomy based on CT ASPECTS imaging criteria alone. Except for NIHSS severity, no other baseline clinical factors could identify which patients were at risk of ASPECTS deterioration. Our study indicates the critical importance of rapid transfer of all stroke patients with suspected LVO to endovascular-capable hospitals. Disclosures M. Mokin: None. R. Gupta: 1; C; Zoll, WellStar foundation. 2; C; Stryker Neurovascular, Covidien, Penumbra, Rapid medical. 6; C; Penumbra, Inc. W. Guerrero: None. D. Rose: 3; C; Boehringer Ingelheim Pharmaceuticals, ChiesiUSA. W. Burgin: None. S. Sivakanthan: None.

\section{P-010 ASSOCIATION OF CLOT BURDEN SCORE WITH RADIOGRAPHIC AND CLINICAL OUTCOMES FOLLOWING SOLITAIRE STENT RETRIEVER THROMBECTOMY: ANALYSIS OF THE SWIFT PRIME TRIAL}

${ }^{1} \mathrm{M}$ Mokin, ${ }^{2} \mathrm{E}$ Levy, ${ }^{2} \mathrm{~A}$ Siddqui, ${ }^{3} \mathrm{M}$ Goyal, ${ }^{4} \mathrm{R}$ Nogueira, ${ }^{5} \mathrm{P}$ Yavagal, ${ }^{6} \mathrm{~V}$ Pereira, ${ }^{7} \mathrm{~J}$ Saver. ${ }^{1}$ University of South Florida, Tampa, FL; ${ }^{2}$ University at Buffalo, Buffalo, NY; ${ }^{3}$ University of Calgary, Calgary, AB, Canada; ${ }^{4}$ Emory University, Atlanta, GA; ${ }^{5}$ University of Miami, Miami, FL; ${ }^{6}$ University of Toronto, Toronto, ON, Canada; ${ }^{7}$ University of California Los Angeles, LoS Angeles, CA

\subsection{6/neurintsurg-2016-012589.52}

Background Clot burden score (CBS) was developed as a tool to evaluate the extent of intracranial thrombus burden in patients with anterior circulation acute ischemic stroke. Its value in predicting radiographic and clinical outcomes in patients treated with endovascular stroke therapy remains unknown.

Objective To evaluate the relationship between CBS and outcomes after stent retriever thrombectomy in the interventional arm of the SWIFT PRIME trial.

Methods CBS was calculated for the endovascular arm (intravenous tPA plus Solitaire stent retriever) of SWIFT PRIME using baseline CTA. The cohort of 69 patients was divided into 3 groups according to their CBS values: CBS 0-5 $(\mathrm{n}=14)$, CBS 6-7 $(\mathrm{n}=23)$ and CBS 8-9 $(\mathrm{n}=32)$. Association between CBS and outcomes following treatment with the Solitaire device was studied.

Results The mean age of the 69 patients who formed the study cohort was $63.2 \pm 13.1$, mean NIHSS score was $16.8 \pm 4.5$, and $55 \%$ were males. There was no difference in clinical characteristics among the 3 groups, except for the baseline ASPECTS ( $\mathrm{P}=0.049$ ). The site of proximal occlusion varied significantly among the 3 groups $(\mathrm{P}<0.001)$. Rates of successful recanalization (TICI $2 \mathrm{~b} / 3$ ), complete recanalization (TICI 3 only), and of good clinical outcome at 3 months were similar among the 3 groups. $(\mathrm{P}=0.24$, $\mathrm{P}=0.35$, and $\mathrm{P}=0.52$, respectively).

Conclusions The combination of IV thrombolysis and stent retriever thrombectomy with the Solitaire device is highly effective in achieving successful recanalization and a good clinical outcome throughout the entire range of CBS values.

Disclosures M. Mokin: None. E. Levy: 4; C; Intratech Medical Ltd., Blockade Medical LLC, Medina Medical. 6; C; Covidien (Medtronic), Abbott, Intratech Medical and Blockade Medical. A. Siddqui: 2; C; Codman \& Shurtleff, Inc., Concentric Medical, ev3/Covidien Vascular Therapies, GuidePoint Global Consulting, Penumbra, Stryker, Pulsar Vascular, MicroVention, Lazarus Effect, Blockade Medical. 3; C; Codman \& Shurtleff, Inc.. 4; C; Hotspur, Intratech Medical, StimSox, Valor Medical, Blockade Medical, and Lazarus Effect. M. Goyal: 1; C; Covidien. 6; C; Covidien. R. Nogueira: 2; C; Stryker. 6; C; Covidien. D. Yavagal: 6; C; Covidien. V. Pereira: 2; C; Medtronic Neurovascular, Stryker. J. Saver: 1; C; 
Covidien. 6; C; Medtronic, Covidien, Stryker, Neuravi, BrainsGate, Pfi zer, Bristol-Myers Squibb, Boehringer Ingelheim.

\section{P-011 IMAGING AND HISTOPATHOLOGY OF THROMBI IN ACUTE ISCHEMIC STROKE: SYSTEMATIC REVIEW AND META-ANALYSIS}

${ }^{1}$ W Brinjikji, ${ }^{2} S$ Duffy, 'D Kallmes. 'Radiology, Mayo Clinic, Rochester, MN; ${ }^{2}$ GallwayMayo Institute of Technology, Gallway, Ireland

\subsection{6/neurintsurg-2016-012589.53}

Background and purpose There has been growing interest in the imaging and histopathology of retrieved thrombi after the introduction of mechanical thrombectomy for the treatment of acute ischemic stroke. We conducted a systematic review and meta-analysis of imaging and histological characteristics of thrombi in acute ischemic stroke.

Materials and methods We identified all studies published between January 2005 and December 2015 that reported findings related to the histological and/or imaging characteristics of thrombi in patients with acute ischemic stroke secondary to large vessel occlusion. The five outcomes examined in this study were 1) the association between histological composition of thrombi and stroke etiology, 2) the association between thrombi histological composition and angiographic outcomes, 3 ) the association between imaging and histological characteristics of thrombi in stroke, 4) the association between imaging characteristics of thrombi and angiographic outcomes and 5) the association between imaging characteristics of thrombi and stroke etiology.

Results There was no significant difference in the proportion of RBC rich thrombi between cardioembolic and large artery atherosclerosis etiologies $(\mathrm{OR}=1.62,95 \% \mathrm{CI}=0.1-28.0$, $\mathrm{P}=0.63$ ). Patients with hyperdense artery sign had a higher odds of having RBC rich thrombi than those without a hyperdense artery sign on $\mathrm{CT}(\mathrm{OR}=9.0,95 \% \mathrm{CI}=2.6-31.2$, $\mathrm{P}<0.01)$. Patients with a good angiographic outcome had a mean HU of 53.0 compared to a mean $\mathrm{HU}$ of 47.3 for patients with a poor angiographic outcome $(\mathrm{MSD}=5.6$, $95 \% \mathrm{CI}=1.1-10.0, \mathrm{P}=0.02)$. There was no association between imaging characteristics and stroke etiology $(\mathrm{OR}=$ $1.13,95 \%$ CI $=0.32-4.00, \mathrm{P}=0.85)$.

Conclusions Hyperdense artery sign is associated with RBC rich thrombi and improved recanalization rates. Further research is needed to determine the association between thrombi composition and stroke etiology as well as revascularization outcomes.

Disclosures W. Brinjikji: None. S. Duffy: 5; C; Neuravi LTD. D. Kallmes: None.

\section{P-012 LONGER WORKING LENGTH OF THE SOLITAIRE RETRIEVAL DEVICE IMPROVES REVASCULARIZATION}

W Holloway, I Akhtar, J Halpin, C Martin, N Akhtar. Marion Bloch Neuroscience Institute, Saint Luke's Hospital of Kansas City, Kansas City, MO

\subsection{6/neurintsurg-2016-012589.54}

Introduction/purpose Endovascular treatment using stent retrievers are now the standard of care in patients with acute ischemic stroke due to proximal middle cerebral artery occlusion. Recent randomized clinical trials have shown stent retriever recanalization rates (TICI 2 b or higher) surpassing $80 \%$.
The Solitaire stent retriever is available in different diameters and lengths. More recently, in August 2014, a $4 \times 40$ device was made available for thrombus retrieval in the US. While there have been many studies comparing the Solitaire to the other mechanical thrombectomy devices, at present, there have been little to no human data comparing the relatively new $4 \times 40$ Solitaire device with the older $4 \times 20$ and $4 \times 15$ devices. In our presentation we will be looking at the cases in which the $4 \times 40$ device was deployed and compare the recanalization rates to those achieved with cases treated with the $4 \times 20$ and $4 \times 15$ in patients with acute stroke.

Materials and methods Materials used were the Solitaire Revascularization device in the sizes $4 \times 40 \mathrm{~mm}, 4 \times 20 \mathrm{~mm}$, and $4 \times 15 \mathrm{~mm}$. All devices are identical in diameter but differ in the working length.

Methods This is a retrospective study of 247 stroke patients who underwent clot retrieval using a $4 \mathrm{~mm}$ diameter Solitaire device as the first device deployed in a case at Saint Luke's Hospital of Kansas City from 2012 till January 2016. Of the 247 total patients, 34 had undergone initial endovascular treatment with the Solitaire $4 \times 40$ device. The remainder were either treated with the $4 \times 20$ or the $4 \times 15$ Solitaire devices. Successful recanalization was determined as having a final TICI score of $2 \mathrm{~b}$ or higher ( $>50 \%$ recanalization). Almost every case was performed with a balloon guide catheter inflated in the neck vasculature with aspiration on the guide catheter during Solitaire retrieval.

Results The following Table 1 shows the recanalization rate with the different Solitaire devices.

\begin{tabular}{lll} 
Abstract P-012 Table 1 & & \\
\hline Size of solitaire Device & Number of patients & $\begin{array}{l}\text { Recanalization rate } \\
\text { (TICl 2b or higher) }\end{array}$ \\
\hline $4 \times 15$ & $(\mathbf{n})$ & $84.38 \%$ \\
$4 \times 20$ & 32 & $88.39 \%$ \\
$4 \times 40$ & 181 & $97.06 \%$ \\
\hline P-Value: 0.1087 & 34 &
\end{tabular}

Conclusions The Solitaire $4 \times 40$ device showed a statistical trend for achieving better recanalization compared to the shorter devices. However due to our small sample size of patients undergoing treatment with the $4 \times 40$, further investigation is warranted to determine whether this result is maintained in larger sample size such as the STRATUS registry. Disclosures W. Holloway: None. I. Akhtar: None. J. Halpin: None. C. Martin: None. N. Akhtar: None.

\section{P-013 USE OF THE SOLITAIRE DEVICE FOR EMERGENCY REVASCULARIZATION OF THE SUPERIOR MESENTERIC ARTERY}

${ }^{1} \mathrm{~J}$ Dalfino, ${ }^{1} \mathrm{~A}$ Paul, ${ }^{2} \mathrm{~J} \mathrm{Hnath} .{ }^{1}$ Neurosurgery, Albany Medical Center, Albany, NY; ${ }^{2}$ Albany Medical Center, Albany, NY

\subsection{6/neurintsurg-2016-012589.55}

Background The Solitaire device (Medtronic) was designed for thrombectomy in acute stroke, but its 4-6 $\mathrm{mm}$ diameter makes it potentially well suited for peripheral embolectomy cases. In this report, we demonstrate the use of a $6 \times 30 \mathrm{~mm}$ Solitaire device to revascularize the superior mesenteric artery in a patient with acute mesenteric ischemia. 